\title{
Low neonatal blood glucose levels in cesarean- delivered term newborns at Khartoum Hospital, Sudan
}

\author{
Shahad M Hussein ${ }^{1}$, Yasir Salih ${ }^{1}$, Duria A Rayis ${ }^{1}$, Jalal A Bilal ${ }^{2}$ and Ishag Adam 1,2,3*
}

\begin{abstract}
Background: Glucose is the main source of energy for organ function in neonates. There are few published recent data on neonatal glucose levels during cesarean delivery.

Methods: A case (cesarean delivery) -control (vaginal delivery) study was conducted at Khartoum Hospital Sudan to compare blood glucose levels of term newborns born after elective cesarean delivery with those born vaginally.

Results: Cord blood glucose levels at delivery were significantly lower in women who had a cesarean delivery compared with those who delivered vaginally $(99.8 \pm 20.6 \mathrm{vs} .106 .8 \pm 11.1 \mathrm{mg} / \mathrm{dl}, \mathrm{P}=0.026)$, but there was no significant difference $(97.8 \pm 16.7$ vs. $102.1 \pm 9.6, P=0.110)$ in newborn glucose levels at 2 hours after delivery between the groups. In linear regression, cesarean delivery $(-6.475 \mathrm{mg} / \mathrm{dl}, \mathrm{P}=0.013)$ and maternal blood glucose levels at the time of delivery $(+0.619 \mathrm{mg}, \mathrm{P}<0.001)$ were significantly associated with mean cord glucose levels.

Conclusion: This study shows that cord blood glucose levels are significantly lower in cesarean-delivered neonates than vaginally-delivered neonates. In addition, cord blood glucose levels are significantly associated with cesarean delivery and maternal blood glucose levels at delivery.
\end{abstract}

Virtual Slides: The virtual slide(s) for this article can be found here: http://www.diagnosticpathology.diagnomx.eu/ vs/2011479878124993

Keywords: Cord, Glucose, Cesarean delivery, Newborn, Sudan

\section{Letter to the Editor}

There has been a recent dramatic increase in the rate of cesarean delivery $[1,2]$. There are many fetal and perinatal complications of cesarean delivery e.g. obesity, allergies, metabolic disturbance, and lower blood glucose levels in the offspring [3-6].

There are few published recent data on neonatal glucose levels during cesarean delivery [6-8]. Glucose is the main source of energy for organ function in neonates. In particular, glucose is an exclusive source of energy for the function of the central nervous system in neonates [9]. The definition and management of neonatal hypoglycemia are controversial and there is

\footnotetext{
* Correspondence: ishagadam@hotmail.com

'Department of Obstetrics and Gynecology, University of Khartoum Khartoum, Sudan

${ }^{2}$ College of Medicine, Qassim University, Buraydah, Kingdom, Saudi Arabia

Full list of author information is available at the end of the article
}

no constant cut-off point for low levels of neonatal glucose [10].

A case-control study was conducted at Khartoum Hospital, Sudan during April to June 2012 to investigate glucose levels in neonates born to women who delivered by elective cesarean. Cases were women delivered by elective cesarean (before labor) and controls were consecutive vaginal deliveries. In both arms of the study, women were at term (37-41 completed weeks of gestation), newborns were $\geq 2500 \mathrm{~g}$ at birth, there was no history of fetal problems, and Apgar scores were 8 or higher at 1 and 5 minutes.

Newborns of mothers with any medical disorder, ante/ intra-partum complications, newborns with signs suggestive of perinatal stress, and instrumental delivery, and those who required intensive resuscitation and care were excluded from both cases and controls.

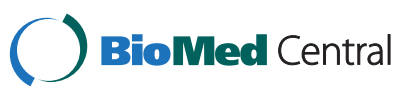


Mothers who underwent cesarean delivery were fasting for at least $6 \mathrm{~h}$ before cesarean delivery. All vaginallydelivered infants were placed at the breast immediately after delivery. Every newborn had a venous cord blood sample obtained from the umbilical cord and another sample was taken $2 \mathrm{~h}$ later from a peripheral vein.

This study received ethical clearance from the Research Board of the Faculty of Medicine, University of Khartoum, Sudan.

After signing an informed consent, demographic data were collected using a pretested questionnaire. Then maternal blood glucose levels at delivery and at 2 hours after delivery, cord glucose levels at delivery and 2 hours after delivery were measured immediately after collection for whole blood glucose levels using the bedside device Accu-Chek ${ }^{\text {Ts }}$ Multiclix (Roche Diagnostics, Mannheim Germany). Start of feeding time, sex of the newborn, neonatal weight, Apgar score, duration of labor, time of mother's fasting, time of starting feeding after delivery, and fluids during labor, were recorded and analyzed.

Data were analyzed using SPSS for windows. Means and proportions of the basic socio-demographic, clinical data and blood glucose levels were compared between women who delivered vaginally and those who had a cesarean delivery using the Student's t-test and $X^{2}$ test, respectively. Linear regression was performed where blood glucose levels (cord, neonatal) were the dependent variable, and other variables (maternal and perinatal) were the independent variables. $\mathrm{P}<0.05$ was considered significant.

The two groups (55 women in each arm) were well matched in their basic characteristics (Table 1). The time

Table 1 Comparison of characteristics of women who delivered vaginally and by cesarean in Khartoum, Sudan

\begin{tabular}{llll}
\hline Variables & $\begin{array}{l}\text { Vaginal } \\
\text { delivery } \\
(\mathbf{n}=\mathbf{5 5})\end{array}$ & $\begin{array}{l}\text { Cesarean } \\
\text { delivery } \\
\mathbf{( n = 5 5 )}\end{array}$ & $\mathbf{P}$ \\
\hline The mean (SD) of & $28.2(4.5)$ & $29.0(4.0)$ & 0.323 \\
Age, years & $1.6(1.4)$ & $1.7(1.3)$ & 0.892 \\
parity & $38.5(1.0)$ & $38.8(1.0)$ & 0.122 \\
Gestational age, weeks & $28.1(1.7)$ & $28.3(2.1)$ & 0.725 \\
Body mass index, kg/cm ${ }^{2}$ & $3.4(1.4)$ & $8.4(1.1)$ & $<0.001$ \\
Fasting time, hours & & & \\
Number (percentage) of & $28(51.0)$ & $24(43.6)$ & 0.276 \\
Educational level $\leq$ & $11(20.0)$ & $11(20.0)$ & 0.549 \\
secondary & $1(1.8)$ & $1(1.8)$ & 0.752 \\
Rural residence & $53(96.4)$ & $46(83.6)$ & 0.052 \\
Lack of antenatal care & $2(3.6)$ & $9(16.4)$ & \\
Normal saline received & & & \\
5\% dextrose received & &
\end{tabular}

of fasting was significantly longer in women who delivered by cesarean than in those who delivered vaginally $(8.4 \pm 1.1)$ vs. $3.4 \pm 1.4$ hours, $\mathrm{P}<0.001$, Table 1$)$.

There were no significant differences in maternal blood glucose levels at delivery and at 2 hours after delivery in the two groups of women. However, cord blood glucose levels were significantly lower in women who delivered by cesarean than in those who delivered vaginally ( $99.8 \pm 20.6$ vs. $106.8 \pm 11.1 \mathrm{mg} / \mathrm{dl}, \mathrm{P}=0.026)$. There was no significant difference in neonatal blood glucose levels at 2 hours after delivery between women who delivered by cesarean and those who delivered vaginally $(97.8 \pm 16.7$ vs. $102.1 \pm 9.6, \mathrm{P}=0.110)$ (Table 2 and Figures 1 and 2).

In linear regression, the factors that were significantly associated with mean cord blood glucose levels were cesarean delivery $(-6.475 \mathrm{mg} / \mathrm{dl}, \mathrm{P}=0.013)$ and maternal glucose at the time of delivery $(+0.619 \mathrm{mg}, \mathrm{P}<0.001$, Table 3). The factors that were significantly associated with mean newborn blood glucose levels at 2 hours after delivery were cord blood glucose $(+0.954 \mathrm{mg}, \mathrm{P}<0.001)$ and maternal glucose at 2 hours after delivery $(+0.161$, $\mathrm{P}=0.004$, Table 4).

A similar finding was reported by Melkie and his colleagues who found that cord blood glucose levels were significantly higher in vaginally-delivered newborns than in cesarean-delivered newborns at delivery, with no significant difference at 2 hours after delivery [7]. Recently, cord blood glucose levels were reported to be lower in cesarean delivery than in vaginal delivery [6]. However, the change in blood glucose levels over the first 2 hours of life was significantly higher in cesarean delivery vs. vaginal delivery (glucose levels alone were not different between the two groups). Additionally, cord blood glucose levels significantly affected the change in blood glucose levels over the first $2 \mathrm{~h}$ after delivery [6]. Similarly, a previous study showed that cord blood glucose values were significantly higher than those of newborns delivered by cesarean. These findings suggest that stress results in release of catecholamines during vaginal delivery $[11,12]$.

The duration of fasting had no significant association with mean maternal blood glucose levels at delivery and

$\begin{aligned} & \text { Table } 2 \text { Maternal and neonatal blood glucose levels in } \\
& \text { vaginal and cesarean deliveries in Khartoum, Sudan }\end{aligned}$
\begin{tabular}{llll} 
Variables & $\begin{array}{l}\text { Vaginal } \\
\text { delivery } \\
(\mathbf{n}=\mathbf{5 5})\end{array}$ & $\begin{array}{l}\text { Cesarean } \\
\text { delivery } \\
(\mathbf{n}=\mathbf{5 5})\end{array}$ & $\mathbf{P}$ \\
& $107.9(14.6)$ & $107.1(17.0)$ & 0.806 \\
\hline Maternal glucose at delivery, mg/dl & $101.5(11.8)$ & $103.4(15.6)$ & 0.450 \\
$\begin{array}{l}\text { Maternal glucose } 2 \text { hours following } \\
\text { delivery, mg/dl }\end{array}$ & $106.8(11.1)$ & $99.8(20.6)$ & 0.026 \\
$\begin{array}{l}\text { Cord glucose, mg/dl } \\
\text { Infant blood glucose at 2 hours, }\end{array}$ & $102.1(9.6)$ & $97.8(16.7)$ & 0.110 \\
mg/dl & & & \\
\hline
\end{tabular}




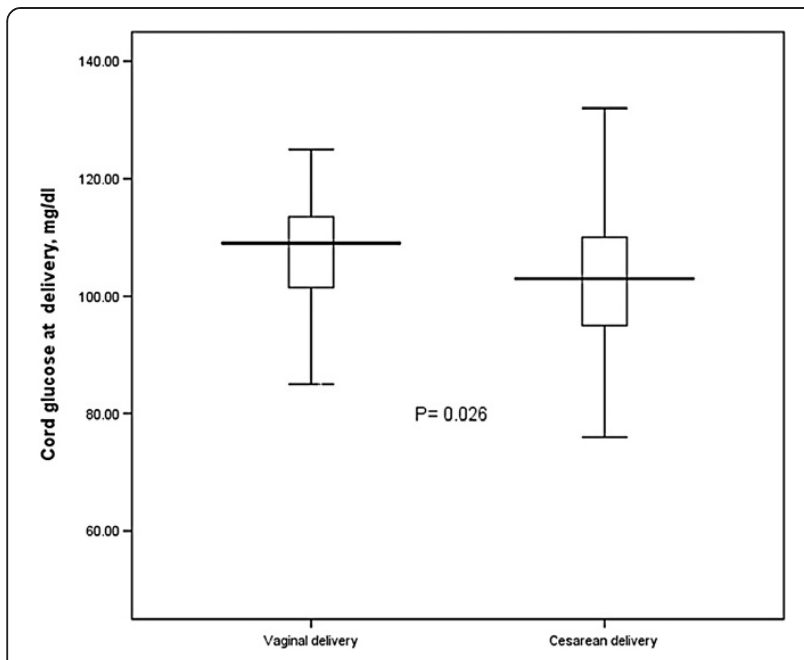

Figure 1 Cord blood glucose levels in vaginal and cesarean deliveries.

at 2 hours following delivery. Maternal blood glucose levels at delivery were significantly associated with maternal blood glucose levels at 2 hours after delivery (+852 mg, $\mathrm{P}<0.001$ ).

In vaginal delivery, there was no correlation between cord blood glucose levels and newborn blood glucose levels 2 hours after delivery $(r=0.257, \mathrm{P}=0.056)$ and the duration of labor $(r=0.238, \mathrm{P}=0.078)$.

During fetal life, cord blood glucose concentrations are correlated with maternal blood glucose concentrations [13]. Fasting time and the catecholamines released during vaginal delivery are possible mechanisms for this

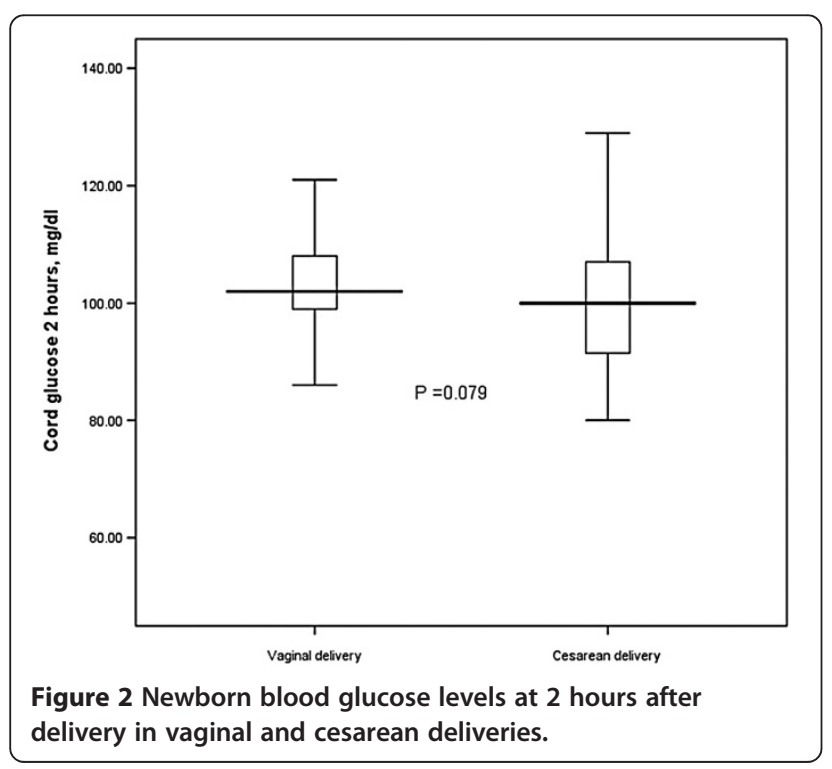

Table 3 Factors affecting cord blood glucose levels using multiple linear regressions

\begin{tabular}{lccc}
\hline Variable & Coefficient & Standard error & P-value \\
\hline Maternal age & 0.429 & 0.357 & 0.232 \\
Parity & -1.017 & 1.128 & 0.369 \\
Gestational age & -0.447 & 1.438 & 0.757 \\
Body mass index & -0.904 & -0.103 & 0.176 \\
Cesarean delivery & -6.475 & -0.194 & 0.013 \\
Maternal glucose at delivery & 0.619 & 0.590 & $<0.001$ \\
Birth weight & 6.370 & 6.411 & 0.323 \\
Fetal gender & 4.475 & 0.140 & 0.065 \\
\hline
\end{tabular}

difference in blood glucose levels [6]. Interestingly, in the current study, although maternal blood glucose levels were not different between women who delivered vaginally and those who delivered by cesarean, both cord blood glucose and newborn blood glucose levels 2 hours after delivery were associated with maternal blood glucose levels. Furthermore, in spite of a longer fasting time in women who delivered by cesarean than in those who delivered vaginally, fasting time was not significantly associated with maternal blood glucose levels. Therefore, newborn blood glucose was correlated with maternal blood glucose, which was not correlated with fasting time, which was assumed to be the more plausible explanation before [6].

In the current study, there was no correlation between blood glucose levels and the duration of labor in women who delivered vaginally. The stress of labor on the mother and newborn increases maternal and fetal catecholamines $[14,15]$. Catecholamine release is higher during normal

Table 4 Factors affecting newborn blood glucose levels at 2 hours of age using multiple linear regressions

\begin{tabular}{lrrr}
\hline Variable & Coefficient & Standard error & P-value \\
\hline Maternal age & 0.014 & 0.114 & 0.683 \\
Parity & 0.004 & 0.358 & 0.917 \\
Gestational age & 0.001 & 0.448 & 0.983 \\
Body mass index & -0.017 & 0.206 & 0.541 \\
Cesarean delivery & 0.001 & 1.801 & 0.992 \\
Maternal glucose at delivery & -0.105 & 0.055 & 0.101 \\
Birth weight & 0.043 & 2.020 & 0.165 \\
Fetal gender & -0.050 & 0.791 & 0.081 \\
Cord glucose & 0.954 & 0.031 & $<0.001$ \\
Maternal glucose at 2 hours & 0.161 & 0.053 & 0.004 \\
Time to start feeding & -0.016 & 0.074 & 0.591 \\
Duration of maternal fasting & 0.029 & 0.314 & 0.651 \\
\hline
\end{tabular}


vaginal delivery than during cesarean delivery [14]. This process forms an essential part of adaptation of the fetus to the extra-uterine environment [16].

\section{Conclusions}

In this study cord blood glucose levels are significantly lower in cesarean-delivered newborns than in vaginallydelivered newborns. In addition, cord blood glucose levels are significantly associated with cesarean delivery and maternal blood glucose levels at delivery.

\section{Competing interest}

The authors declare that they have no competing interests.

\section{Authors' contributions}

SMH and IA designed the study. YS, JAB and DAR conducted the clinical work. IA, JAB and IA performed the statistical analyses. All of the authors read and approved the final manuscript.

\section{Author details}

'Department of Obstetrics and Gynecology, University of Khartoum, Khartoum, Sudan. ${ }^{2}$ College of Medicine, Qassim University, Buraydah, Kingdom, Saudi Arabia. 'Faculty of Medicine, University of Khartoum, Khartoum, Sudan.

Received: 24 March 2014 Accepted: 21 May 2014

Published: 9 June 2014

\section{References}

1. Adam I: Epidemic /pandemic of Cesarean delivery: the scope of the problem. Int J Health Sci (Qassim) 2014. in press.

2. Abbaker AO, Abdullahi H, Rayis DA, Imam AM, Adam I: An Epidemic of Cesarean Deliveries at Khartoum Hospital in Sudan with Over Two-Fifths of Neonates Delivered through the Abdomen. J Women's Health Issues Care 2013, 2:6

3. Bråbäck L, Ekéus C, Lowe AJ, Hjern A: Confounding with familial determinants affects the association between mode of delivery and childhood asthma medication - a national cohort study. Allergy Asthma Clin Immunol 2013, 9:14.

4. Atasay B, Ergun H, Okulu E, Mungan Akın I, Arsan S: The association between cord hormones and transient tachypnea of newborn in late preterm and term neonates who were delivered by cesarean section. J Matern Fetal Neonatal Med 2013, 26:877-880.

5. Li HT, Zhou YB, Liu JM: The impact of cesarean section on offspring overweight and obesity: a systematic review and meta-analysis. Int J Obes (Lond) 2013, 37:893-899.

6. Marom R, Dollberg S, Mimouni FB, Berger I, Mordechayev N, Ochshorn Y, Mandel D: Neonatal blood glucose concentrations in caesarean and vaginally delivered term infants. Acta Paediatr 2010, 99:1474-1477.

7. Melkie M, Yigeremu M, Nigussie P, Teka T, Kinde S: Is the difference in neonatal blood glucose concentration of caesarian and vaginally delivered term infants requiring separated reference intervals? BMC Research Notes 2012, 5:519.

8. McGowan JE: Neonatal hypoglycemia. Pediatr Rev 1999, 20:6-15

9. Inder T: How low can I go? The impact of hypoglycemia on the immature brain. Pediatrics 2008, 122:440-441.

10. Alkalay AL, Sarnat HB, Flores-Sarnat L, Elashoff JD, Farber SJ, Simmons CF: Population meta-analysis of low plasma glucose thresholds in full-term normal newborns. Am J Perinatol 2006, 23:115-119.

11. Lagercrantz H, Slotkin TA: The "stress" of being born. Sci Am 1986, 254:100-107.

12. Ha“gnevik K, Faxelius G, Irestedt L, Lagercrantz H, Lundell B, Persson B: Catecholamine surge and metabolic adaptation in the newborn after vaginal delivery and caesarean section. Acta Paediatr Scand 1984, 73:602-609.

13. Cornblath M, Schwartz R: Factors influencing glucose in the neonates. In Disorders of carbohydrate metabolism in infancy. 3rd edition. Edited by Cornblath M, Schwartz R. Boston: Blackwell Scientific Publications; 1991:58.
14. Ronca AE, Abel RA, Ronan PJ, Renner KJ, Alberts JR: Effects of labor contractions on catecholamine release and breathing frequency in newborn rats. Behav Neurosci 2006, 120:1308-1314.

15. Lederman RP, McCann DS, Work B Jr, Huber MJ: Endogenous plasma epinephrine and norepinephrine in last-trimester pregnancy and labor. Am J Obstet Gynecol 1977, 129:5-8.

16. Ronca $A E$, Abel RA, Alberts JR: Perinatal stimulation and adaptation of the neonate. Acta Paediatr 1996, 416(Suppl):8-15.

doi:10.1186/1746-1596-9-112

Cite this article as: Hussein et al:: Low neonatal blood glucose levels in cesarean-delivered term newborns at Khartoum Hospital, Sudan.

Diagnostic Pathology 2014 9:112

\section{Submit your next manuscript to BioMed Central and take full advantage of:}

- Convenient online submission

- Thorough peer review

- No space constraints or color figure charges

- Immediate publication on acceptance

- Inclusion in PubMed, CAS, Scopus and Google Scholar

- Research which is freely available for redistribution 